\title{
Low dielectric constant nanoporous poly(methyl silsesquioxane) using poly(styrene-block-2-vinylpyridine) as a template
}

\author{
Chang-Chung Yang ${ }^{\mathrm{a}}$, Pei-Tzu Wu ${ }^{\mathrm{a}}$, Wen-Chang Chen ${ }^{\mathrm{a}, \mathrm{b}, *}$, Hsin-Lung Chen $^{\mathrm{c}}$ \\ ${ }^{a}$ Department of Chemical Engineering, National Taiwan University, 106 Taipei, Taiwan, ROC \\ ${ }^{\mathrm{b}}$ Institute of Polymer Science and Engineering, National Taiwan University, 106 Taipei, Taiwan, ROC \\ ${ }^{\mathrm{c}}$ Department of Chemical Engineering, National Tsing-Hua University, 300 Hsinchu, Taiwan, ROC
}

Received 14 February 2004; received in revised form 22 May 2004; accepted 31 May 2004

\begin{abstract}
Low dielectric constant nanoporous poly(methyl silsesquioxane) (PMSSQ) was prepared through the templating of an amphiphilic block copolymer, poly(styrene- $b$-2-vinylpyridine) (PS- $b$-P2VP). The experimental and theoretical studies suggest that the intermolecular hydrogen bonding interaction is existed between the PMSSQ precursor and PS- $b$-P2VP. The result of modulated differential scanning calorimeter (MDSC) indicates the miscible hybrid of the PMSSQ precursor/PS- $b$-P2VP. The miscible hybrid and the narrow thermal decomposition of the PS- $b$-P2VP lead to nanopores in the prepared films from the results of transmission electronic microscopy (TEM), atomic force microscopy (AFM), and small angle X-ray scattering (SAXS). The effects of the loading ratio and the PS block volume ratio $\left(f_{\mathrm{PS}}: 0.74,0.46\right.$ and 0.35 ) on the morphology and properties of the prepared nanoporous PMSSQ films were investigated. The AFM and TEM studies suggest that the uniform pore morphology should be prepared from a modest porogen loading level for the optimum intermolecular hydrogen bonding. The PS- $b$-P2VP with a smaller $f_{\mathrm{PS}}$ requires a higher loading level to obtain the uniform pores. The refractive index and dielectric constant of the prepared nanoporous films could be tuned by the loading ratio in the range of $1.361-1.139$ and $2.359-1.509$, respectively. However, both properties are independent of the $f_{\mathrm{PS}}$. The prepared study demonstrates the control of the morphology and properties of the nanoporous films through the polymer structure.
\end{abstract}

(C) 2004 Elsevier Ltd. All rights reserved.

Keywords: PMSSQ; PS- $b-\mathrm{P} 2 \mathrm{VP}$; Nanopore

\section{Introduction}

Nanoporous thin films have been extensively studied recently because of their potential applications as low dielectric constant $(k)$ materials [1-7] or antireflective optical coating [8]. For the case of low $k$ applications, uniform pore size less than $15 \mathrm{~nm}$ was suggested to avoid the moisture absorption and be considerably smaller than the minimum dimensions for deep-submicron integrated circuit devices $[9,10]$. One of the potential approaches for creating nanopores in thin films is through the templating agent, such as norbornene-derivative [4-6], hyperbranched

\footnotetext{
* Corresponding author. Address: Department of Chemical Engineering, Polymer Science and Engineering, National Taiwan University, No. 1, Sec. 4, Roosevelt Rd., 106 Taipei, Taiwan, ROC. Tel.: + 886-223-628-398; fax: +886-223-623-040.

E-mail address: chenwc@ntu.edu.tw (W.C. Chen).
}

polymers [11-14], amphiphilic block copolymer (ABC) [8-10,15-21], and cyclodextrin [22,23].

The ABC could be used as an ideal pore generator (porogen) since they offer the advantages of microphase morphologies for controlling the pore size and shape. The successful porogens for obtaining low dielectric constant nanoporous methyl silsesquioxane films included poly(methyl methacrylate -block-dimethylaminoethyl methacrylate) (PMMA- $b$-PDMAEMA) [8-10] and poly(ethylene oxide-block-propylene oxide-block-ethylene oxide) (PEO- $b$ PPO- $b$-PEO) $[18,19]$. The pore size of the obtained nanoporous film was estimated to be less than $10 \mathrm{~nm}$ [8-10,18-19]. For the above studies [8-10,15-21], the chemical interaction between the MSSQ and the ABC was regarded as the important factor for controlling the resulted pore size distribution. Intermolecular hydrogen bonding [8-10,18,19] or covalent bonding [4-6] significantly improved the miscibility of the PMSSQ/ABC hybrid and thus significant 


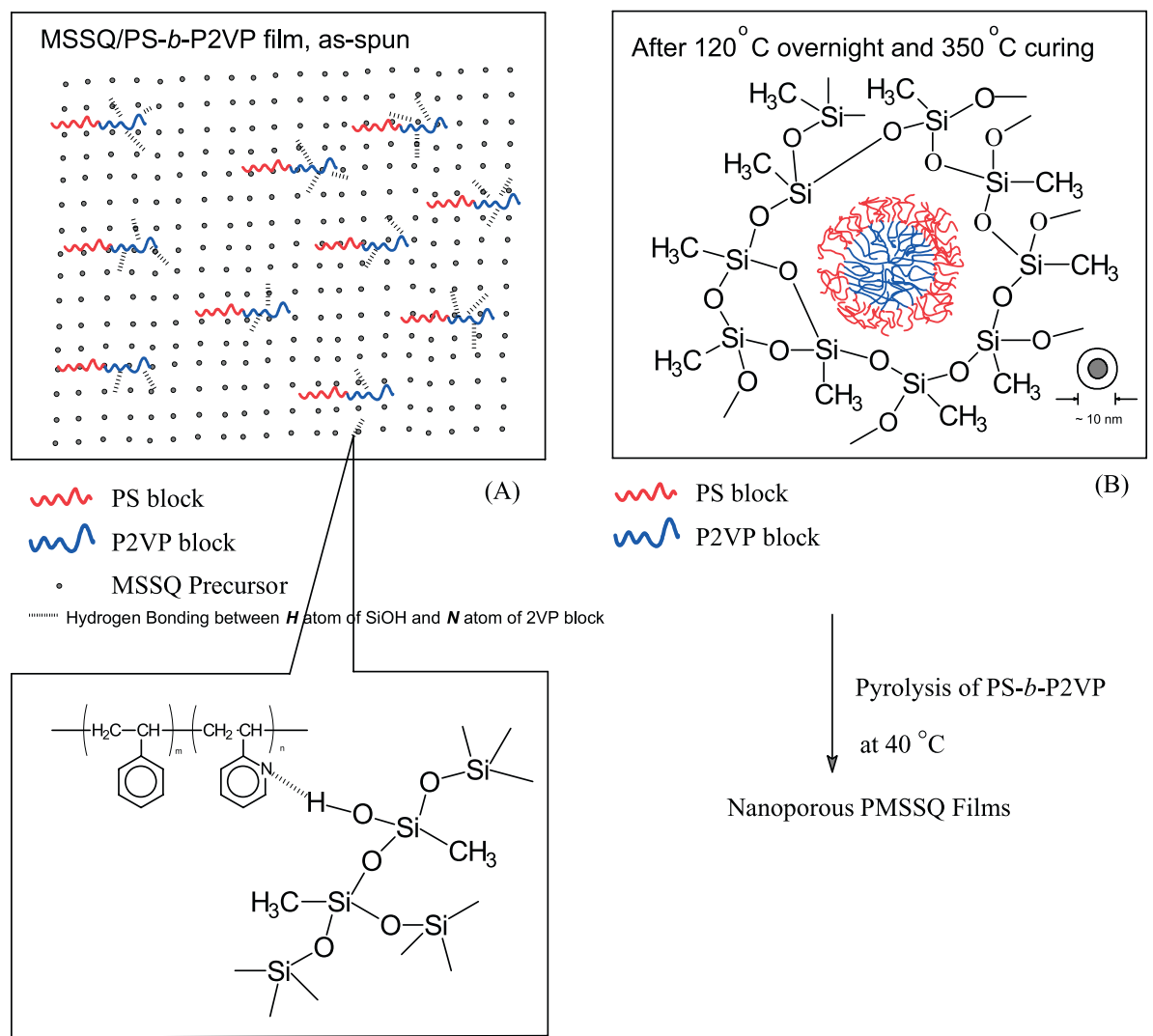

Fig. 1. Scheme for preparing the nanoporous PMSSQ film by the templating of the PS- $b$-P2VP.

aggregation would not occur during curing. The amphiphilic characteristic of the MSSQ precursor is shifted to hydrophobic because of the polycondensation of the $\mathrm{Si}-\mathrm{OH}$ groups to the $\mathrm{Si}-\mathrm{O}-\mathrm{Si}$ linkages during the thermal curing. Hence, microphase separation is expected through the hydrophobicamphiphilic interaction between the PMSSQ and the ABC. The $\mathrm{ABC}$ in the microphase domain was then removed by thermal curing at high temperature and left pores in the films. Although the $\mathrm{ABC}$ has been successfully used as a pore generator for nanoporous films, the control of the morphology and properties of the nanoporous PMSSQ films through the polymer structures has not been fully explored yet. Besides, the experimental and theoretical investigations on the chemical interaction between the PMSSQ precursor and the $\mathrm{ABC}$ are required to be further investigated.

In this study, various segment or loading ratios of poly(styrene-block-2-vinylpyridine) (PS- $b$-P2VP) were used as the porogen for obtaining the nanoporous PMSSQ. Fig. 1 shows the scheme for preparing the nanoporous PMSSQ films by the templating of the PS- $b$-P2VP. Miscible hybrid materials of the PMSSQ precursor and PS- $b$-P2VP would be obtained through the proposed intermolecular hydrogen bonding between the 2VP moiety and the $\mathrm{Si}-\mathrm{OH}$ end group. Theoretical analysis on the hydrogen bonding interaction was performed on the model compounds of $\mathrm{Si}\left(\mathrm{CH}_{3}\right)_{3} \mathrm{OH}$ and pyridine, which were used as the models for the PMSSQ precursor and PS- $b$-P2VP, respectively. The
Fourier transform infrared (FTIR) spectra of the prepared PMSSQ/ABC hybrids were also used to verify the hydrogen bonding interaction. The miscibility between the PMSSQ and the porogen was further analyzed by the modulated DSC (MDSC). The effects of the loading ratio and the PS block volume ratio ( $f_{\mathrm{PS}}: 0.74,0.46$ and 0.35$)$ on the morphology and properties of the prepared nanoporous PMSSQ films were investigated. The morphology of the prepared nanoporous PMSSQ films was investigated by AFM, TEM, and SAXS. The correlation of the refractive index and dielectric constant of the prepared nanoporous films with the loading ratio of the $\mathrm{ABC}$ was discussed.

\section{Experimental}

\subsection{Materials}

Styrene (St, Fluka, 99\%), 2-vinylpyridine (2VP, Acros, 97\%) were distillated from dibutylmagnesium (Aldrich, 1.0 M solution in heptane) under reduced pressure. Tetrahydrofuran (THF, Acros, 99.9\%) was distillated from sodium (Aldrich, 30-35 wt\% dispersion in paraffin wax) and benzophenone (Aldrich, $99+\%$ ) mixture. sec-Butyllithium (sec-BuLi, Acros, 1.3 M in cyclohexane/hexane) and methyl trimethoxysilane (MTMS, Aldrich, 95\%) were used as received. 


\subsection{Synthesis of the amphiphilic block copolymer, PS-b-} $P 2 V P$

The PS- $b$-P2VP was synthesized by sequential living anionic polymerization as reported in the literature [24]. Three kinds of the PS- $b$-P2VP with different $\mathrm{f}_{\mathrm{PS}}$ (volume fraction of the PS segment) were prepared in this study with the following molecular structure data (number-average molecular weight distribution $\left(M_{\mathrm{n}}\right)$, polydispersity (PDI), and $\left.f_{\mathrm{PS}}\right)$ : I $(15,000,1.25$, and 0.74$)$, II $(15,400,1.14$, and $0.46)$, and III $(13,900,1.25$, and 0.35$)$.

\subsection{Synthesis of poly(methyl silsesquioxane) precursor (PMSSQ)}

The synthesis and characterization of the PMSSQ precursor was according to our previous report [25,26]. Here, the PMSSQ precursor was prepared from MTMS in THF using the mole ratio of the water to MTMS equal to 3.0 and the $\mathrm{pH}$ of 2.0. The obtained PMSSQ precursor consisted of both symmetric (cage-like) and non-symmetry (networklike) structures, as identified by the FTIR spectrum. The molecular weight $\left(M_{\mathrm{w}}\right.$ and $\left.M_{\mathrm{n}}\right)$ of the prepared PMSSQ were 3880 and 700, respectively, as determined by gel permeation chromatography (GPC). The $\mathrm{OH}$ content of the prepared PMSSQ precursor estimated from the FTIR analysis was $6.72 \%$ from the comparison with a reference PMSSQ sample from Gelest Co. with a reported $\mathrm{OH}$ content of $5 \%$.

\subsection{Preparation of the nanoporous PMSSQ films by the templating of the $A B C$}

The PMSSQ precursor solution (10 wt $\%$ in tetrahydrofuran, THF) and the porogen PS- $b$-P2VP solution (5 wt $\%$ in THF) were mixed with different ratio for the present study. The ratio of the porogen to the total solid (PMSSQ + PS- $b$ P2VP) was varied from 0 to $60 \mathrm{wt} \%$ with $10 \mathrm{wt} \%$ interval in the present study. The solution filtered through a $0.5 \mu \mathrm{m}$ MFS-25 PTFT filter (Advantec MFS, Inc.) was spun-coated onto 4 in cleaned single-polished $\mathrm{Si}(100)$ wafer at $1500 \mathrm{rpm}$ for $30 \mathrm{~s}$. The samples prepared were then cured at 25, 50, 80, and $100{ }^{\circ} \mathrm{C}$ for $30 \mathrm{~min}$ sequentially and baked at $120{ }^{\circ} \mathrm{C}$ overnight. The pyrolysis of the porogen was carried out in a quartz furnace purged with nitrogen at $350{ }^{\circ} \mathrm{C}$ for $30 \mathrm{~min}$ and followed by $400{ }^{\circ} \mathrm{C}$ for one and half hours. The obtained nanoporous PMSSQ thin films through templating of the PS- $b$-P2VP I, II, and III, were named as the P1, P2 and P3, respectively. The number $(\mathbf{X})$ following the $\mathbf{P 1 - X}$ is the weight percentage of PS- $b$-P2VP loading.

\subsection{Characterization}

The FTIR spectra of the prepared thin films were recorded by a DIGILAB FTS-3500GX spectrophotometer. The molecular weight distribution of the prepared materials, was determined by a GPC equipped with PLgel $5 \mu \mathrm{m}$ MIXED-C and D columns, a RI detector, and the elution solvent of $\mathrm{THF}$ at $1 \mathrm{ml} / \mathrm{min}$.

The thermal decomposition temperatures $\left(T_{\mathrm{d}}\right)$ of the prepared materials were characterized by a TA Instrument TGA 951 thermogravimetric analyzer (TGA) at a heating rate of $10{ }^{\circ} \mathrm{C} / \mathrm{min}$ from room temperature to $900{ }^{\circ} \mathrm{C}$. Glassy transition temperatures $\left(T_{\mathrm{g}}\right)$ of the prepared PS- $b$-P2VP and PMSSQ/PS- $b$-P2VP nanocomposites was obtained by a TA Instrument DSC Q1000 differential scanning calorimeter (DSC) with modulated DSC mode at a heating rate of $5{ }^{\circ} \mathrm{C} /$ min from 75 to $145^{\circ} \mathrm{C}$. A multimode AFM instrument (Digital Instrument Model Nanoscope IIIa) was operating in the tapping mode with the silicon cantilever/tips (NanoSensors, NCH-type) to probe the surface morphology of the prepared thin films. The silicon tips with diameter of $10-20 \mathrm{~nm}$, force constant of $42 \mathrm{~N} / \mathrm{m}$, and resonance frequency of $250-270 \mathrm{kHz}$ were used. The TEM diagram of the prepared hybrid film was obtained from the JEOL (model number: 2002-EX) with an accelerating voltage of $100 \mathrm{kV}$. Ultrathin samples of $80 \mathrm{~nm}$ obtained through the precision ion polishing system were used for the TEM measurement.

The small angle X-ray (SAXS) experiment was conducted at room temperature. The X-ray source of SAXS, an $18 \mathrm{KW}$ rotating anode X-ray generator (Rigaku) equipped with a rotating anode $\mathrm{Cu}$ target, was operated at $200 \mathrm{~mA}$ and $40 \mathrm{KV}$. The incident X-ray beam was monochromated by a pyrolytic graphite and a set of three pinhole inherent collimators were used so that the smearing effects inherent in slit-collimated small angle X-ray cameras can be avoided. The scattered intensity was detected by a two-dimensional position sensitive detector (ORDELA Model 2201X, Oak Ridge Detector Laboratory Inc., USA.) with $256 \times 256$ channels (active area $20 \times 20 \mathrm{~cm}^{2}$ with $\sim 1 \mathrm{~mm}$ resolution). All data were corrected by the background (dark current and empty beam scattering) and the sensitivity of each pixel of the area detector. The area scattering pattern has been radially averaged to increase the photon counting efficiency compared with one-dimensional linear detector. The intensity profile was output as the plot of the scattering intensity $(I)$ vs. the scattering vector, $q=4 \pi / \lambda \sin (\theta / 2)$ ( $\theta=$ scattering angle). A baked powder of P2-30 sample was used for the SAXS measurement.

The dielectric constant of the prepared materials was determined as below. An aluminum layer with the thickness of $5000 \AA$ was coated on the prepared thin film by a ULVAC EBX-6D thermal evaporator with an attached mask, and probed by a Keithley $590 \mathrm{C}-\mathrm{V}$ analyzer with a sweeping frequency of $100 \mathrm{kHz}$ to determine the dielectric constant. An n\&k analyzer (model number: 1200, n\&k Technologies, Inc.) was used to measure the film thickness and refractive index of the prepared thin films at the wavelength ranging from 190 to $900 \mathrm{~nm}$.

The porosity of the prepared nanoporous PMSSQ films 


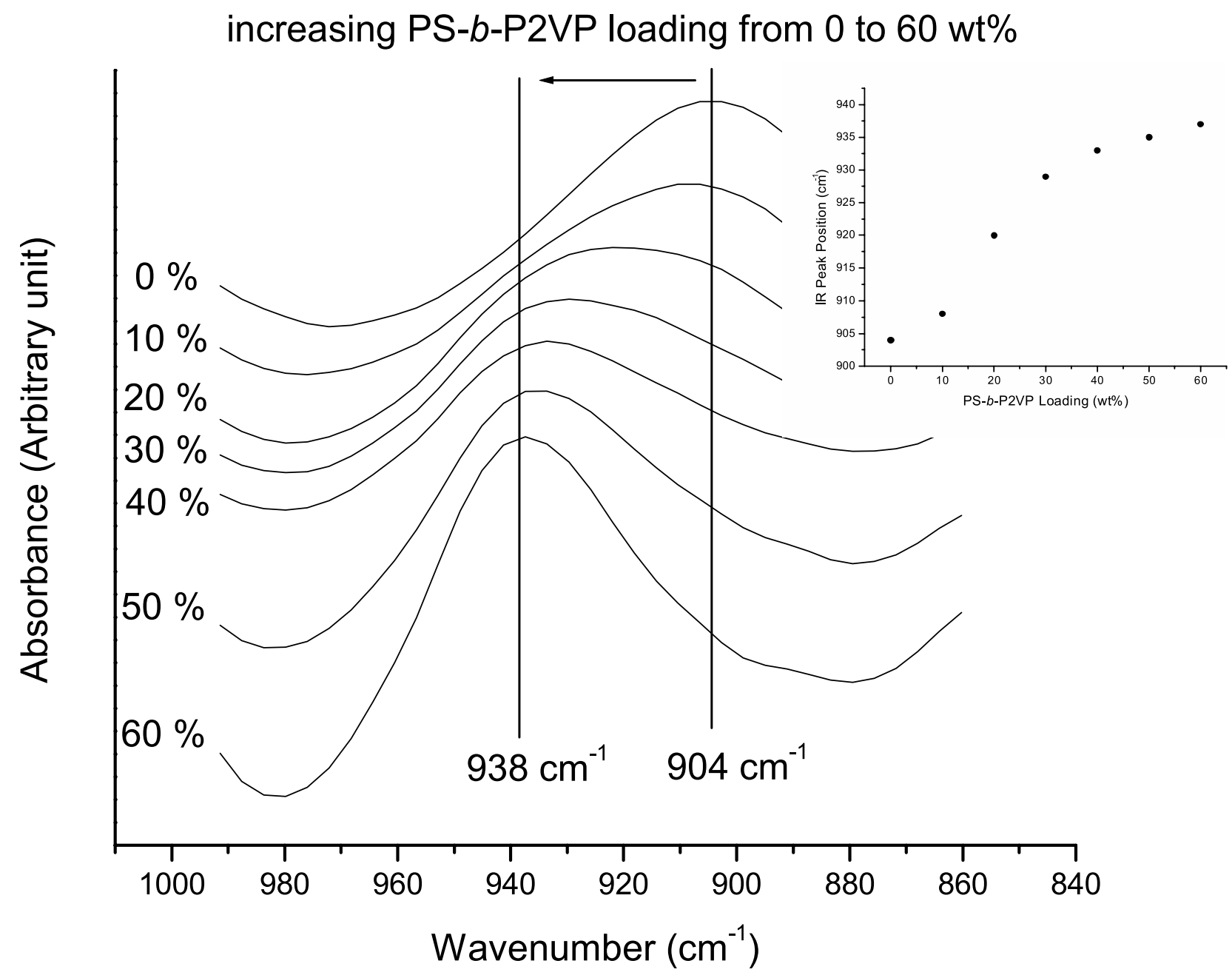

Fig. 2. FTIR absorption spectra of as-spun PMSSQ precursor/PS- $b$-P2VP(II) hybrid thin films in the wavenumber ranging from 860 to $990 \mathrm{~cm}^{-1}$. Inset shows the position variation of the $\mathrm{Si}-\mathrm{O}$ IR peak with the PS- $b$-P2VP loading.

determined by the Maxwell-Garnett model [3] as Eq. (1):

$\frac{n^{2}-1}{n^{2}+2}=(1-\Delta p) \frac{n_{\mathrm{MSSQ}}^{2}-n_{\mathrm{air}}^{2}}{n_{\mathrm{MSSQ}}^{2}+2 n_{\text {air }}^{2}}$

where $n, n_{\mathrm{MSSQ}}$, and $n_{\text {air }}$ are the refractive index of the prepared nanoporous MSSQ thin films, the parent MSSQ thin film and the air, respectively. $\Delta p$ is the porosity of nanoporous MSSQ film relative to the parent MSSQ thin film.

\subsection{Theoretical analysis on the model compounds}

All the geometries of the studied model compounds of the $\mathrm{Si}\left(\mathrm{CH}_{3}\right)_{3} \mathrm{OH}$ and pyridine were optimized to the local minima, which were confirmed by the frequency calculations at the B3LYP/6-31 $+\mathrm{G}^{*}$ level of theory and performed on GAUSSIAN 98 [27]. The final energies of the studied systems were obtained and corrected with zeropoint vibrational energies by the harmonic-oscillator approximation. The calculation of bond length and vibrational frequency was also based on these optimized geometries.

\section{Results and discussion}

Fig. 2 shows the FTIR absorption spectra of the as-spun PMSSQ/PS- $b$-P2VP(II) hybrid thin films. The absorption band shown in Fig. 2 is assigned to the $\mathrm{Si}-\mathrm{O}$ stretching on the $\mathrm{Si}-\mathrm{OH}$ bond of the PMSSQ [25-26,28]. As observed in Fig. 2, the position of the $\mathrm{Si}-\mathrm{O}$ band gradually shifts from 904 to $938 \mathrm{~cm}^{-1}$ as increasing the loading of the PS- $b$ P2VP. It indicates the formation of the hydrogen bonding between the $\mathrm{N}$ of the $2 \mathrm{VP}$ segment and $\mathrm{H}$ of the $\mathrm{Si}-\mathrm{OH}$ of the PMSSQ, as suggested by Fig. 1(A). The suggested hydrogen bonding decreases the bond strength between the $\mathrm{H}$ and $\mathrm{Si}-\mathrm{O}$ of the $\mathrm{Si}-\mathrm{OH}$ bond and thus results in the shifting of the $\mathrm{Si}-\mathrm{O}$ stretching band to a higher wavenumber.

The strength of the intermolecular interaction of the hybrid materials is very important for the morphology and 
properties of the resulted nanoporous films. To verify the hydrogen bonding interaction for the prepared hybrid materials, molecular simulation software, GAUSSIAN 98, was used to calculate the corresponding molecular parameters of the model compounds for the studied hybrid materials. The simulation results on the interaction for the $\mathrm{Si}\left(\mathrm{CH}_{3}\right)_{3} \mathrm{OH}$ and pyridine (the model of PMSSQ/PS- $b$ $\mathrm{P} 2 \mathrm{VP}$ ) showed that the differences of the energy of system $(E)$ between the isolated and the hydrogen bonded are negative, $-5.9 \mathrm{kcal} / \mathrm{mol}$. It suggests that there is an attraction force between the studied two model compounds due to the decrease in the system energy. The hydrogen bonding between hydrogen of $\mathrm{Si}\left(\mathrm{CH}_{3}\right)_{3} \mathrm{OH}$ and nitrogen of pyridine has the bond length of $1.912 \AA$ and results in the increase of the $\mathrm{O}-\mathrm{H}$ bond length of the $\mathrm{Si}-\mathrm{OH}$ from 0.967 to $0.984 \AA$. The suggested hydrogen bonding stabilizes the system of $\mathrm{Si}\left(\mathrm{CH}_{3}\right)_{3} \mathrm{OH} /$ pyridine is concluded from the decrease in the system energy, $-5.9 \mathrm{kcal} / \mathrm{mol}$. This hydrogen bonding weakens the bond strength between the $\mathrm{H}$ and the $\mathrm{Si}-\mathrm{O}$ and thus the theoretical vibration frequency of $\mathrm{Si}-\mathrm{O}$ bond $\left(\nu_{\mathrm{Si}-\mathrm{O}}\right)$ increases from 909 to $927 \mathrm{~cm}^{-1}$. It has the same trend as the experimental results shown in Fig. 2. The above theoretical analysis demonstrates that the chemical interaction between the PMSSQ and the PS- $b$ $\mathrm{P} 2 \mathrm{VP}$ (or $\mathrm{Si}\left(\mathrm{CH}_{3}\right)_{3} \mathrm{OH}$ and pyridine) is a typical hydrogen bonding. The hydrogen bond existing between silanol group and pyridine was also observed by the blend of poly (styrene- $b$-vinylphenyldimethylsilanol) and poly(vinylpyridine) [29]. Another important factor that could affect the miscibility of the hybrid is the molecular weight of the P2VP block of PS- $b$-P2VP and PMSSQ. Matsen has proposed that the macrophase separation of the block copolymer/homopolymer blend could be prevented if the molecular weight of the homopolymer is comparable or smaller to the miscible segment of the block copolymer [30]. In the present case, the molecular weight of the PMSSQ precursor and P2VP of the PS- $b$-P2VP (II) determined from GPC are 3880 and 8320, respectively. Since the molecular weight data are determined by comparing with PS standard, the molecular weight of the PMSSQ and P2VP segment might be comparable and thus would not result in significant macrophase separation.

Fig. 3 shows the FTIR spectra of the PMSSQ/PS- $b$ $\mathrm{P} 2 \mathrm{VP}(\mathbf{I I})$ hybrid thin films in the wavenumber range of 650 to $1650 \mathrm{~cm}^{-1}$ at the curing temperature of 25 (as-spun), 120 (after baked overnight), and $400{ }^{\circ} \mathrm{C}$ (after complete pyrolysis of the PS- $b$-P2VP), respectively. The intensity of absorption peak at $938 \mathrm{~cm}^{-1}$ assigned to the $\mathrm{Si}-\mathrm{O}$ stretching of the $\mathrm{Si}-\mathrm{OH}$ bond decreases as the temperature increases and completely disappears at $400{ }^{\circ} \mathrm{C}$. This suggests the condensation reaction of the $\mathrm{Si}-\mathrm{OH}$ bond of the PMSSQ precursor to form the $\mathrm{Si}-\mathrm{O}-\mathrm{Si}$ bond. The peak at $1100 \mathrm{~cm}^{-1}$ is splits into two peaks on increasing the curing temperature, which is assigned to the $\mathrm{Si}-\mathrm{O}-\mathrm{Si}$ stretching. The two peaks at 1130 and $1030 \mathrm{~cm}^{-1}$ are assigned to the symmetric (e.g. cage-like) and non-

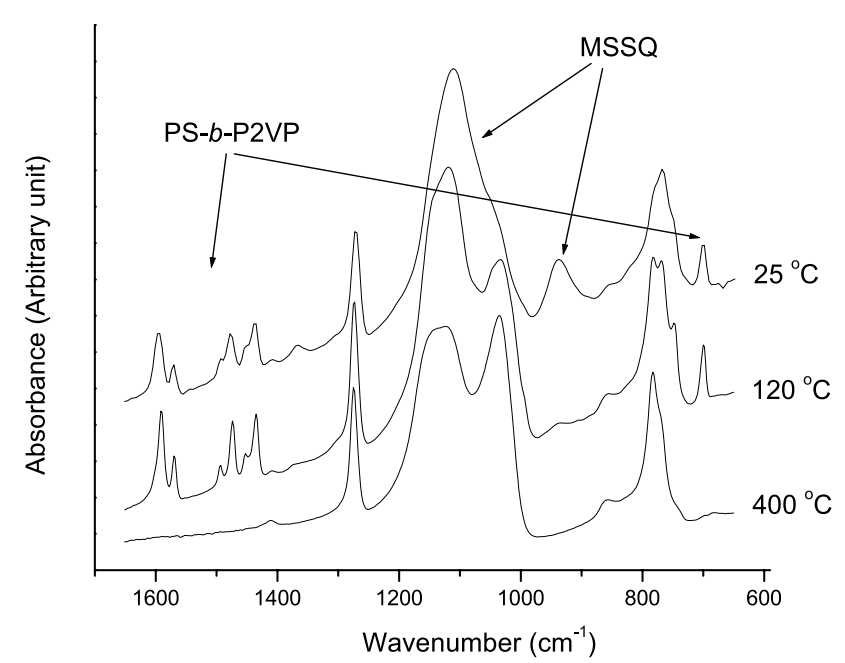

Fig. 3. FTIR spectra of the prepared PMSSQ/PS- $b-\mathrm{P} 2$ VP(II) hybrid films at 25 (as-spun), 120 (overnight), and $400{ }^{\circ} \mathrm{C}$ (after complete pyrolysis), respectively.

symmetric structures (e.g. network), respectively. Such structural transformation is similar to that reported in the literature $[8-10,25,26,28,31,32]$. PMSSQ are known to be composed of random branched structure, ladder structure, and cage structure. Parts of the cage-like structure undergo the secondary polycondensation, and therefore result in structural opening and subsequent chain extension and cross-linking reactions [28]. Such structure transformation has been observed by WAXS [28] or FTIR [25,26], which would result in significant difference on the mechanical properties and electronic properties. The characteristic peaks of the PS- $b$-P2VP at 700 , and 1434 to $1590 \mathrm{~cm}^{-1}$ completely disappeared after pyrolysis at $400{ }^{\circ} \mathrm{C}$.

The hydrogen bonding between the PMSSQ and the PS$b$-P2VP may interfere with the $\mathrm{Si}-\mathrm{OH}$ condensation reaction of the PMSSQ and result in the retardation of the symmetry/non-symmetry structural transformation. Fig. 4 shows the FTIR spectra of the prepared nanoporous films in the wavenumber range of $900-1250 \mathrm{~cm}^{-1}$ by varying the loading of the PS- $b$-P2VP (II). The non-symmetry structural ratio decreases with increasing the PS- $b$-P2VP loading ratio, which indicates the retardation of the symmetry/nonsymmetry structural transformation. The retardation of the structural transformation suggests that an intermolecular interaction exists between the PMSSQ and PS- $b$-P2VP. The retention of the symmetrical structure could result in the reduction of the refractive index or dielectric constant.

Fig. 5 shows the modulated DSC (MDSC) curves of the PMSSQ/PS- $b$-P2VP(II) nanocomposites. The glassy transition temperature $\left(T_{\mathrm{g}}\right)$ of the pure PS- $b$-P2VP determined from MDSC is $100{ }^{\circ} \mathrm{C}$. Hence, the PS- $b$-P2VP copolymer is mobile under the curing temperature of $120^{\circ} \mathrm{C}$ for the preparing the hybrid materials. For the case of PMSSQ/PS$b$-P2VP (30\%), a broad featureless curve is shown. It might be because the domain is too small or the porogen loading is too low. A recent report on the MDSC study of the PMSSQ/ 


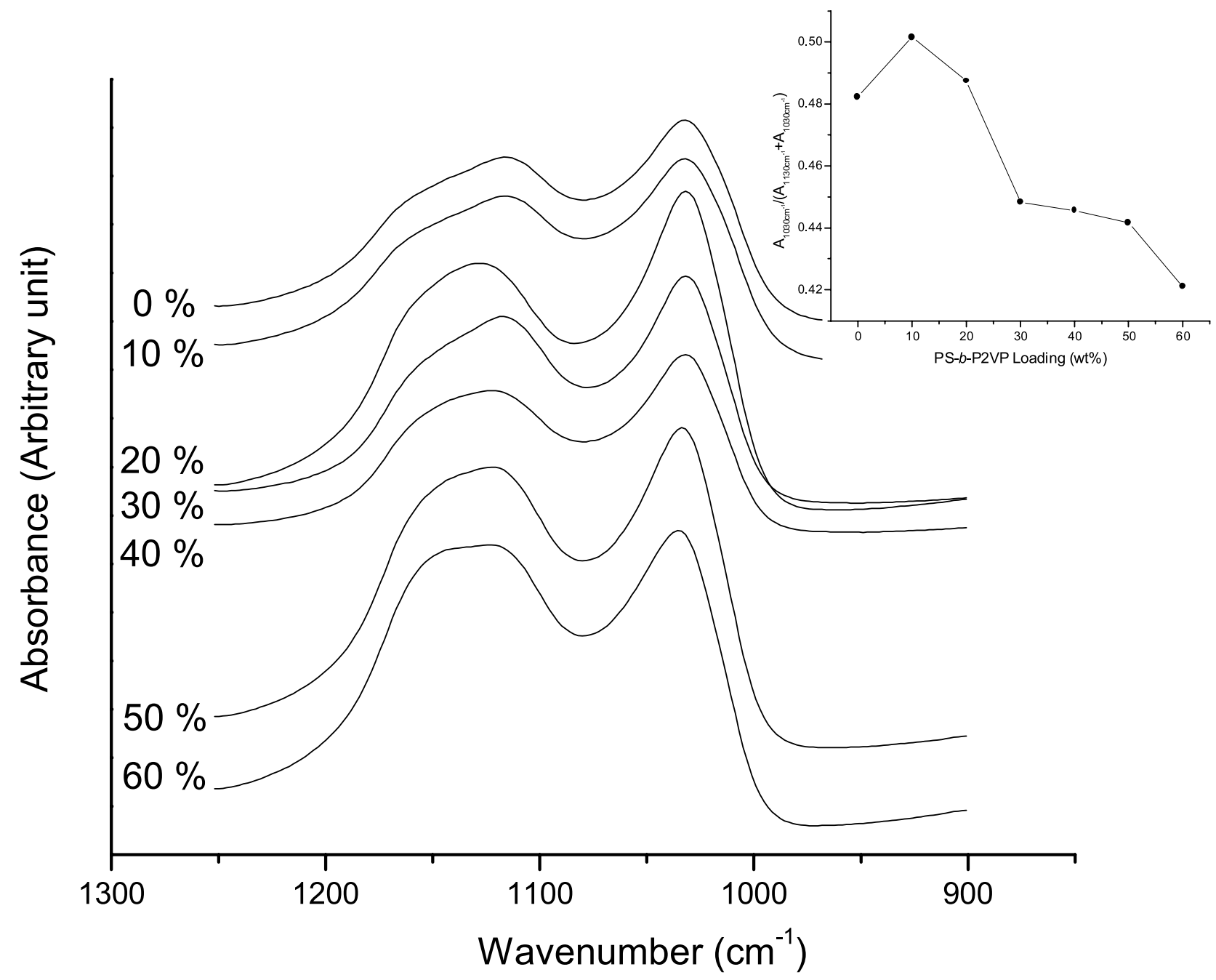

Fig. 4. FTIR spectra of the prepared nanoporous films in the wavenumber range of $900-1250 \mathrm{~cm}^{-1}$. Inset shows the variation of non-symmetrical structural ratio of PMSSQ with the porogen loading.

P(MMA-co-DMAEMA) also shows a similar result [10]. As the loading of the PS- $b$-P2VP increases, a single $T_{\mathrm{g}}$ of $110{ }^{\circ} \mathrm{C}$ due to PS- $b$-P2VP is shown in the case of PMSSQ/ PS- $b$-P2VP $(50 \%)$. The higher $T_{\mathrm{g}}$ of the PMSSQ/PS- $b$ $\mathrm{P} 2 \mathrm{VP}(50 \%)$ than the parent PS- $b$-P2VP might be due to the inorganic matrix of the PMSSQ or intermolecular hydrogen bonding.

The inset of Fig. 5 shows the TGA curves of the prepared PS- $b$-P2VP(II) copolymer. The PS- $b$-P2VP has only one $T_{\mathrm{d}}$ about $387^{\circ} \mathrm{C}$. The degree on the cross-linking of the PMSSQ determined by IR analysis was $50 \%$ at $100{ }^{\circ} \mathrm{C}$ and $95 \%$ at $390{ }^{\circ} \mathrm{C}$, respectively $[31,32]$. Hence, as the pyrolysis of the PS- $b$-P2VP occurs, the condensation and crosslinking reaction almost complete to maintain the stable pore structure. The collapse of the symmetry structure of the PMSSQ is around $450{ }^{\circ} \mathrm{C}[31,32]$, which is larger than the $T_{\mathrm{d}}$ of the PS- $b$-P2VP. Therefore, the PS- $b$-P2VP would be a good candidate as a porogen for preparing nanoporous materials from the above thermal analysis.

Fig. 6 shows the TEM diagrams of the prepared P2-30
(Fig. 6(a)) and P2-60 (Fig. 6(b)). The pore structure is distinguishable at modest porogen loading of P2-30 in Fig. 6(a) but much more ambiguous for the case of Fig. 6(b). The pore size estimated from Fig. 6(a) and is $8.56 \pm 0.64 \mathrm{~nm}$. The distinguished pore structure was resulted from by the intermolecular hydrogen bonding and the suitable thermal characteristics. The pore size shown in Fig. 6(a) could also be estimated from its chemical structure as below. The reduced radius of the gyration $\left(\left[\left\langle s^{2}\right\rangle_{\mathrm{w}} / \bar{M}_{\mathrm{w}}\right]^{1 / 2}\right)$ of the atactic polystyrene in the glassy state according to small angle neutron scattering is a constant of 0.0278 [33]. Since the size of the 2-vinylpyridine is similar to that of the styrene, the radius of gyration of the PS- $b$-P2VP with $M_{\mathrm{n}}=15,400$ is estimated to be $3.4 \mathrm{~nm}$ according to the above relationship. Hence, the diameter of the theoretical PS- $b-\mathrm{P} 2 \mathrm{VP}$ is estimated to be $6.8 \mathrm{~nm}$, which is close to the pore size determined from Fig. 6(a).

Fig. 7(a)-(g) shows the AFM diagrams of the parent PMSSQ, PS- $b$-P2VP, and their hybrids at different compositions. Both films of pure PMSSQ and pure PS- $b$-P2VP are 


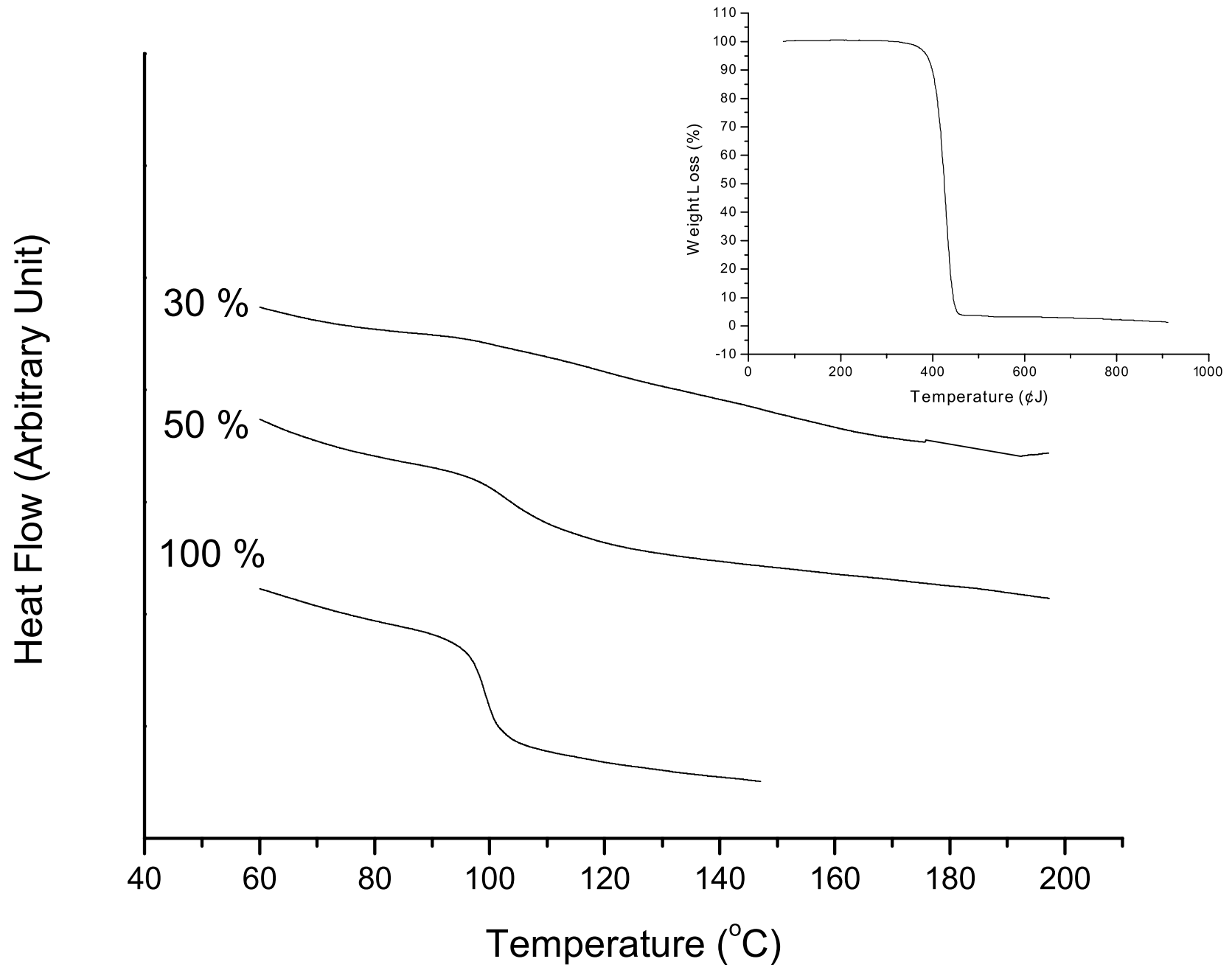

Fig. 5. Modulated DSC curves of the prepared nanocomposite thin films of PMSSQ/PS- $b$-P2VP(II): (a) pure PS- $b$-P2VP; (b) PMSSQ/PS- $b$-P2VP with 50 wt $\%$ PS- $b$-P2VP; (c) PMSSQ/PS- $b-\mathrm{P} 2 \mathrm{VP}$, with $30 \mathrm{wt} \%$ PS- $b$-P2VP. Insert shows the TGA curves of the PS- $b$-P2VP copolymers.

uniform without any significant macrophase separation on the surface. Fig. 7(b) $-(\mathrm{g})$ shows the AFM diagram of nanoporous PMSSQ thin films, P2-10-P2-60, prepared from the PMSSQ/PS- $b$-P2VP hybrids. For the case of the P2-10, there is no clear domain size shown on the surface. As the porogen loading ratio increases, uniform spherical pores with the size around $13-15 \mathrm{~nm}$ are shown on the surface of P2-20 Fig. 7(c), P2-30 Fig. 7(d) and P2-40 Fig. 7(e). Note that the pore size is estimated from the AFM height profile image. However, the aggregation size on the surface increases significantly as the porogen loading increases to $50 \mathrm{wt} \%$, P2-50 Fig. 7(f), and more seriously in the case of the P2-60 Fig. 7(g). As the porogen loading ratio is too small (e.g. P2-10) or too large (e.g. P2-50 or P260), there is not enough hydrogen bonding interaction between the PMSSQ and the PS- $b$-P2VP for preventing aggregation. Thus, the macrophase separation might occur in the hybrid after curing and results in a large domain size after pyrolysis. However, an optimum intermolecular bonding exists for the cases of $\mathbf{P 2 - 2 0} \sim \mathbf{P 2}-\mathbf{4 0}$ and results in a miscible hybrid. If there is no chemical interaction between PMSSQ and ABC, macrophase separation would be occurred. The study on the PMSSQ/(PMMA- $b$ PDMAEMA) hybrid suggested that homogeneous hybrid could not be occurred if the DMAEMA mole ratio was less than $15 \mathrm{~mol} \%$. Besides, 20 or $30 \mathrm{~mol} \%$ of DMAEMA was the optimum mole ratio for producing uniform nanopores, which was similar to the present case of PS- $b$-P2VP [9]. The results of the AFM and TEM studies suggest the uniform pore morphology of the nanoporous thin films should be prepared from templating a modest porogen loading level.

Fig. 8 shows the SAXS profiles of the nanoporous PMSSQ films P2-30 before (30a) and after baking (30b) at $450{ }^{\circ} \mathrm{C}$. The scattering profile of the baked sample is characterized by a primary scattering peak at $0.32 \mathrm{~nm}^{-1}$ coupled with a shoulder situating at calculated $3^{1 / 2}$ the position of the primary peak. The shallow hump denoted by ' $i=1$ ' is the first-order form factor peak associated with the scattering from individual pores. Form factor scattering depends on the geometric characteristics of the pores, including the shape, the average dimension, and the dimension distribution. Because the pores are most likely 


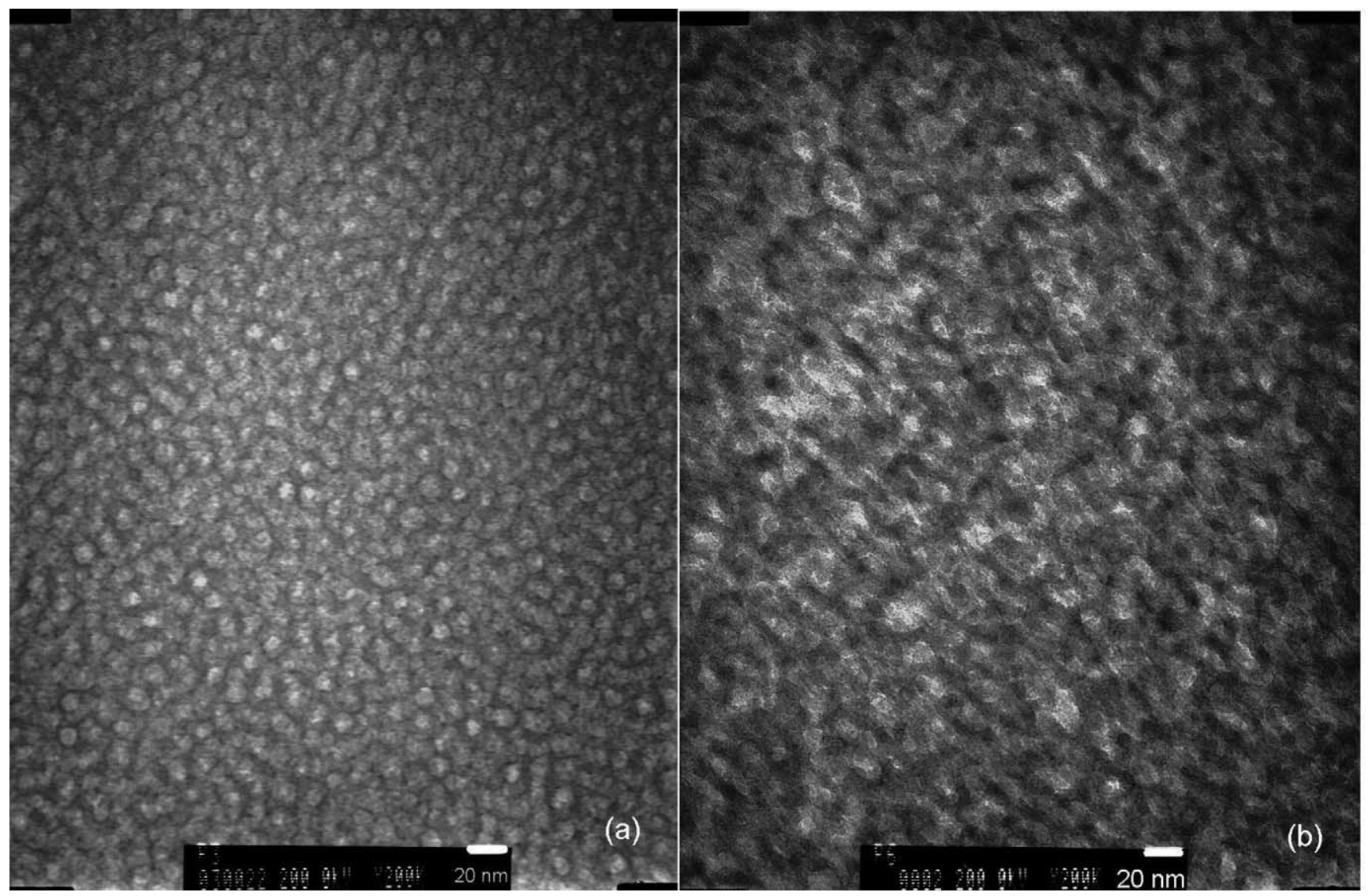

Fig. 6. TEM diagrams of the porous PMSSQ thin films: (a) P2-30 and (b) P2-60.

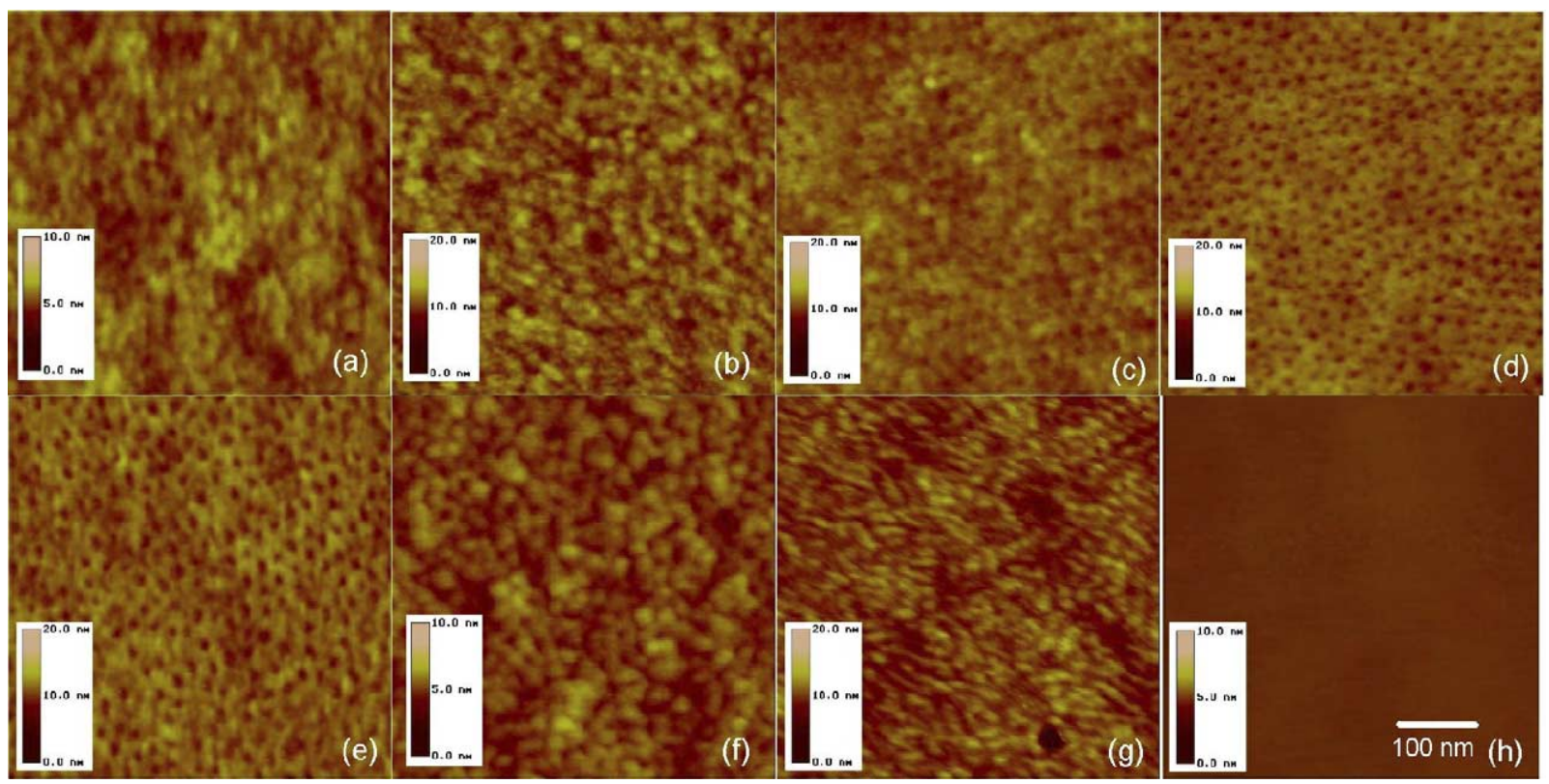

Fig. 7. AFM diagrams of the parent PMSSQ, PS- $b-P 2 V P$, and the porous PMSSQ films: (a) parent PMSSQ; (b) P2-10; (c) P2-20; (d) P2-30; (e) P2-40; (f) P250; (g) P2-60; (h) PS- $b$-P2VP. 


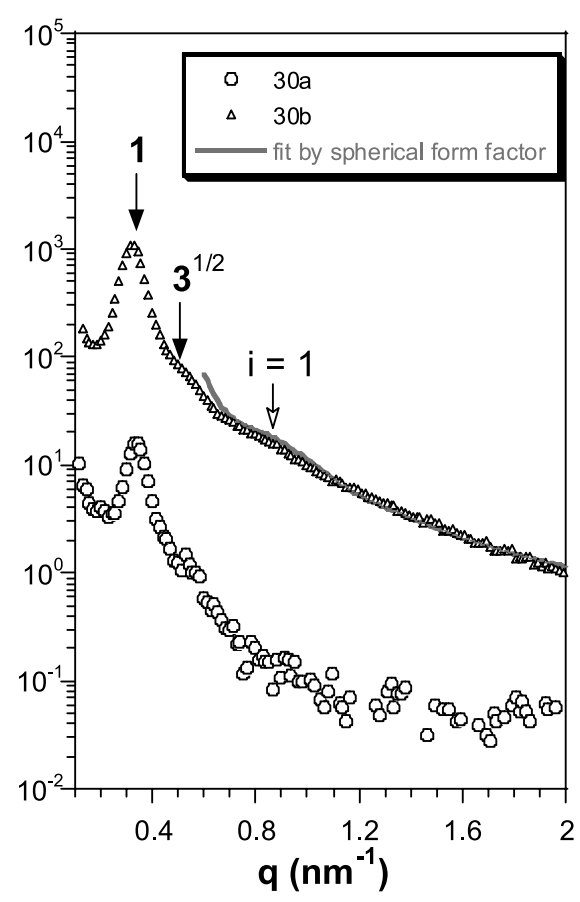

Fig. 8. SAXS profiles of the nanoporous PMSSQ films P2-30 before (30a) and after baking (30b) at $450{ }^{\circ} \mathrm{C}$.

spherical in shape based upon the TEM and AFM observation, the observed form factor profile was fitted by the formula of spherical form factor given by Ref. [34]

$f_{\mathrm{s}}^{2}(q)=\left[V_{\mathrm{sph}} \Delta \rho \Phi(U)\right]^{2}$

where $V_{\text {sph }}$ is the volume of the sphere, $\Delta \rho$ is the electron density contrast between the sphere and the matrix and $\Phi(U)$ is the scattering function given by

$\Phi(U)=\frac{3(\sin U-U \cos U)}{U^{3}}$

where $U=q R$ with $R$ being the radius of the sphere. Distribution of $R$ can be taken into account in calculating the scattering pattern so that the experimentally observed profile can be simulated more accurately. In this case, the average form factor is given by Ref. [35]

$\left\langle f_{\mathrm{s}}^{2}(q)\right\rangle=\frac{\int_{0}^{\infty} f_{\mathrm{s}}^{2}(q) P(R) \mathrm{d} R}{\int_{0}^{\infty} P(R) \mathrm{d} R}$

where $P(R)$ is the distribution function for the sphere radius. Gaussian distribution function is adopted here for $P(R)$, viz.

$P(R) \sim \exp \left[\frac{-(R-\langle R\rangle)^{2}}{2 \sigma_{\mathrm{R}}^{2}}\right]$

where $\langle R\rangle$ is the average radius and $\sigma_{\mathrm{R}}$ is the standard deviation of the size distribution. The result of the form factor fitting is displayed as the solid curve in Fig. 8. The spherical form factor is seen to fit the experimentally observed form factor profile well, supporting that the nanopores are spherical in shape. $\langle R\rangle$ of the pores and $\sigma_{\mathrm{R}}$ obtained from the fit are 5.8 and $1.2 \mathrm{~nm}$, respectively. The average radius closely agrees with that estimated by TEM and AFM observations.

The relative positions (i.e. $1: 3^{1 / 2}$ ) of the two lattice peaks observed from the nanoporous sample attests that the spherical pores are most likely BCC packed with an interpore distance of ca. $19.5 \mathrm{~nm}$. This distance is virtually identical with the inter-domain distance found in the unbaked sample, indicating that PS- $b$-P2VP/MSSQ is an effective template with the nanoporous structure largely prescribed by the template structure. The microdomain ordering in the template is however poorer in that the higher-order lattice peak is not clearly identified in the corresponding SAXS profile. The improvement of longrange order in the nanoporous sample may be caused during baking as the sample actually undergoes an annealing in the course of the thermal treatment.

Fig. 9(a)-(d) shows the AFM diagrams of the prepared P1-30, P1-50, P3-30 and P2-50, respectively. By comparing P1-30 of Fig. 9(a) with P2-30 of Fig. 7(d) and P3-30 of Fig. 9(c), uniform spherical pores only appear on P1-30 and P230 which templates with a larger $f_{\mathrm{PS}}$ (a longer PS block). However, when the PS- $b$-P2VP loading up to a high content, P3-50 of Fig. 9(d) shows pore structure but P2-50 of Fig. 7(f) and P1-50 of Fig. 9(b) shows a significant aggregation domain and a worm-like structure, respectively. Note that the P1, P2, and P3 were prepared from the templating of the PS- $b$-P2VP with the volume fraction of the PS segment $\left(f_{\mathrm{PS}}\right)$ equal to $0.74,0.46$, and 0.35 , respectively. Hence, the above results suggest that the PS segment of the P3-30 might not be long enough for forming uniform pores in comparison of the cases of the P1-30 and P2-30. However, such problem could be resolved at a high loading level, as shown in the

Table 1

Properties of the prepared nanoporous PMSSQ films, P1, P2 and P3

\begin{tabular}{|c|c|c|c|c|c|c|}
\hline & $\begin{array}{l}\text { Loading } \\
(\%)\end{array}$ & $\begin{array}{l}\text { Film thickness } \\
\text { (§) }\end{array}$ & $\begin{array}{l}R_{\mathrm{q}} \\
(\mathrm{nm})\end{array}$ & $n$ & $k$ & $\begin{array}{l}\Delta p \\
(\%)^{1}\end{array}$ \\
\hline PMSSQ & 0 & 1788 & 0.294 & 1.361 & 2.359 & 0 \\
\hline P1-10 & 10 & 2178 & 0.755 & 1.347 & 2.267 & 3.5 \\
\hline P1-20 & 20 & 2512 & 0.888 & 1.313 & 2.138 & 12.2 \\
\hline P1-30 & 30 & 2824 & 1.210 & 1.284 & 2.039 & 19.7 \\
\hline P1-40 & 40 & 2891 & 0.900 & 1.238 & 1.843 & 31.9 \\
\hline P1-50 & 50 & 2941 & 1.481 & 1.179 & 1.715 & 48.0 \\
\hline P1-60 & 60 & 3045 & 1.471 & 1.139 & 1.506 & 59.3 \\
\hline P2-10 & 10 & 2866 & 0.661 & 1.339 & 2.341 & 5.6 \\
\hline P2-20 & 20 & 2902 & 0.611 & 1.314 & 2.182 & 12.0 \\
\hline P2-30 & 30 & 3376 & 0.864 & 1.294 & 1.988 & 17.0 \\
\hline P2-40 & 40 & 3351 & 0.685 & 1.242 & 1.981 & 30.7 \\
\hline P2-50 & 50 & 4145 & 0.744 & 1.217 & 1.758 & 37.6 \\
\hline P2-60 & 60 & 4119 & 1.073 & 1.154 & 1.603 & 54.9 \\
\hline P3-10 & 10 & 2954 & 0.346 & 1.328 & 2.269 & 8.3 \\
\hline P3-20 & 20 & 3196 & 0.439 & 1.301 & 2.170 & 15.3 \\
\hline P3-30 & 30 & 3886 & 0.436 & 1.279 & 2.111 & 21.0 \\
\hline P3-40 & 40 & 3735 & 0.621 & 1.222 & 2.084 & 36.2 \\
\hline P3-50 & 50 & 4073 & 0.656 & 1.207 & 1.810 & 40.3 \\
\hline P3-60 & 60 & 4332 & 0.633 & 1.141 & 1.527 & 58.7 \\
\hline
\end{tabular}

\footnotetext{
${ }^{\mathrm{a}}$ Estimated from Eq. (1).
} 


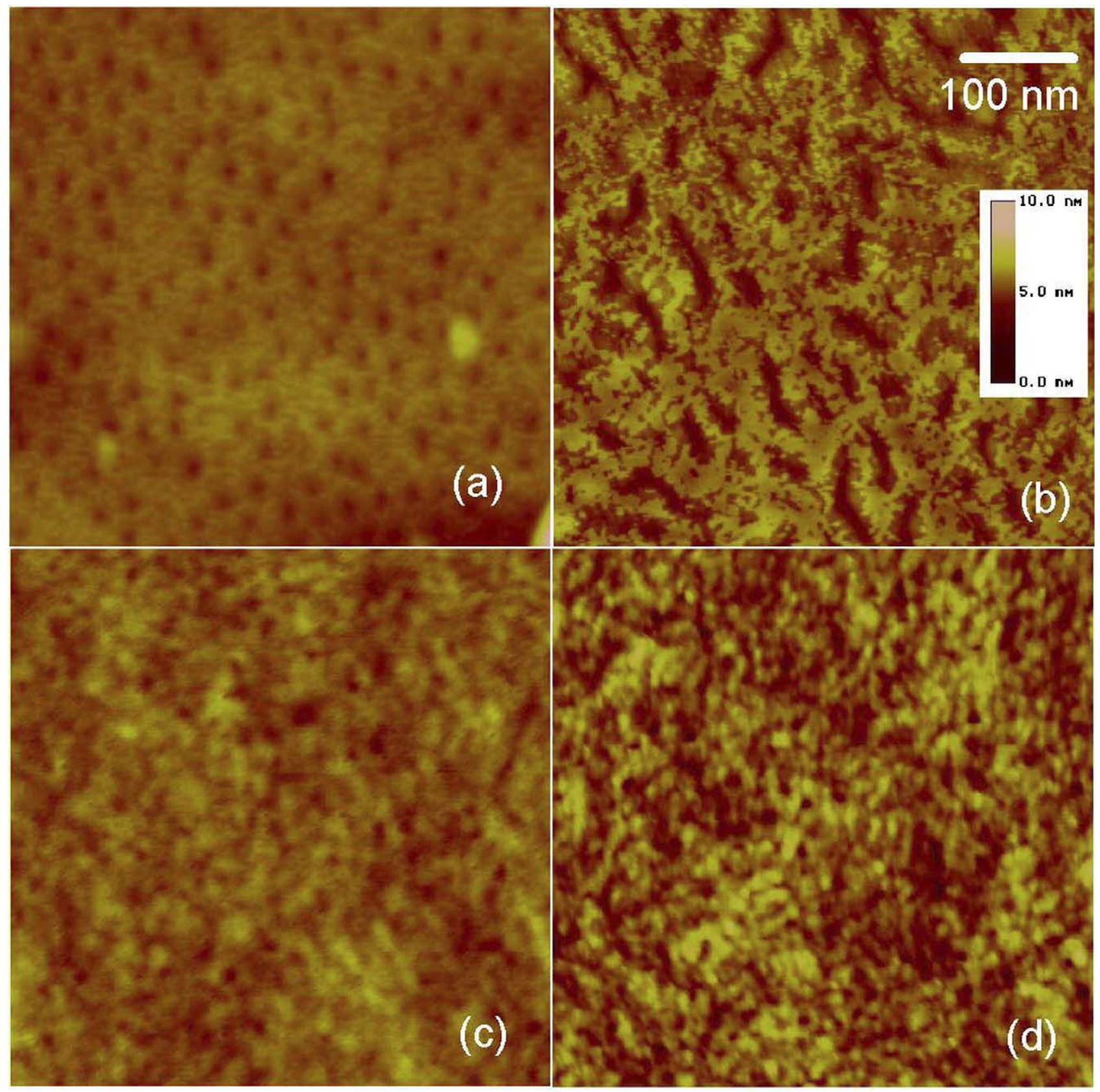

Fig. 9. AFM diagrams of the nanoporous PMSSQ thin films: (a) P1-30, (b) P1-50, (c) P3-30, and (d) P3-50.

case of P3-50. It demonstrates that the $f_{\mathrm{PS}}$ significantly influences the morphology of the nanoporous films.

Fig. 10 shows the surface roughness (root mean square roughness, $R_{\mathrm{q}}$ ) of the prepared $\mathbf{P 1}, \mathbf{P} 2$, and $\mathbf{P 3}$ from the AFM measurement. It shows that the order of the $R_{\mathrm{q}}$ is $\mathbf{P 1}>\mathbf{P 2}>\mathbf{P 3}$. It suggests the nanoporous MSSQ thin films are rougher if the porogen PS- $b$-P2VP with a longer PS block. The degree of intermolecular hydrogen bonding dominates the morphology of the PMSSQ/PS- $b$-P2VP hybrid and results in the difference on the surface roughness.

Figs. 11 and 12 show the variation of refractive index and dielectric constant of the prepared P1, P2 and P3 with the loading level of the PS- $b$-P2VP, respectively. The refractive index of thin films linearly decreases from 1.361 to 1.139 as the PS- $b$-P2VP loading increases from 0 to $60 \mathrm{wt} \%$. Similar to the trend of the refractive index, the dielectric constant decreases from 2.359 to 1.506 as the PS- $b$-P2VP loading increases from 0 to $60 \mathrm{wt} \%$. The decreasing trend demonstrates the porosity of the nanoporous PMSSQ thin film listed in Table 1 could be controlled by the PS- $b$-P2VP loading level. However, there is no significant variation on the refractive index or dielectric constant between the PS- $b$ P2VP with different $f_{\mathrm{PS}}$. This suggests that the refractive index or dielectric constant is controlled by the loading ratio 


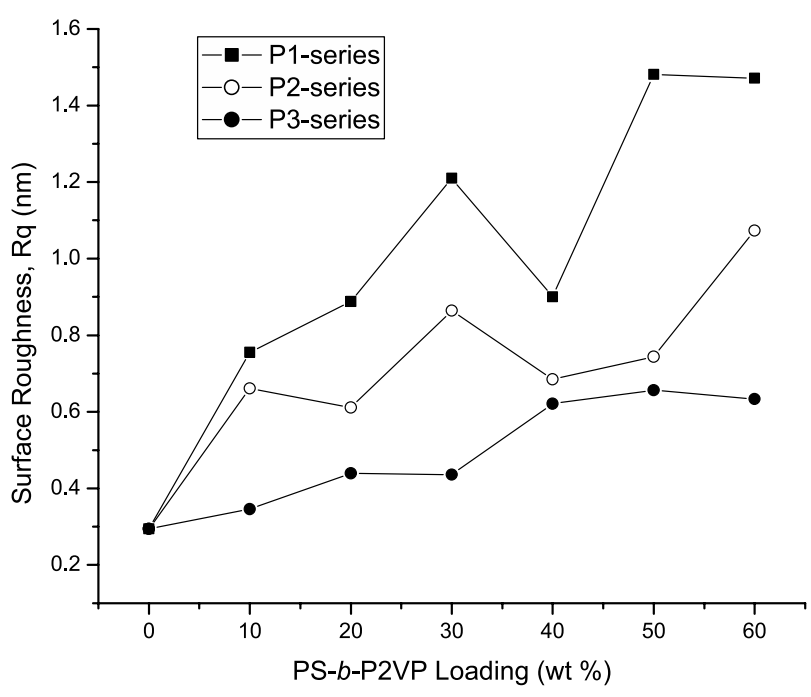

Fig. 10. Root-mean-square roughness $\left(R_{\mathrm{q}}\right)$ of the nanoporous PMSSQ thin films, P1, P2 and $\mathbf{P 3}$ from the AFM analysis.

of the PS- $b$-P2VP. The segment ratio of the PS- $b-\mathrm{P} 2 \mathrm{VP}$ plays a significant role on the pore morphology but is less significant on the electronic properties.

\section{Conclusions}

In this study, nanoporous PMSSQ films were successfully prepared through the templating of the ABC, PS- $b$ P2VP. Both theoretical analysis and experimental results suggest that the strong intermolecular hydrogen bonding existed in the PMSSQ/PS- $b$-P2VP hybrid and prevented the macrophase separation in the hybrid. The miscible hybrid and the narrow thermal decomposition of the PS- $b-\mathrm{P} 2 \mathrm{VP}$ lead to uniform nanopores in the prepared films. Uniform pore morphology should be prepared from a modest porogen loading level. The segment ratio of the PS- $b$ -

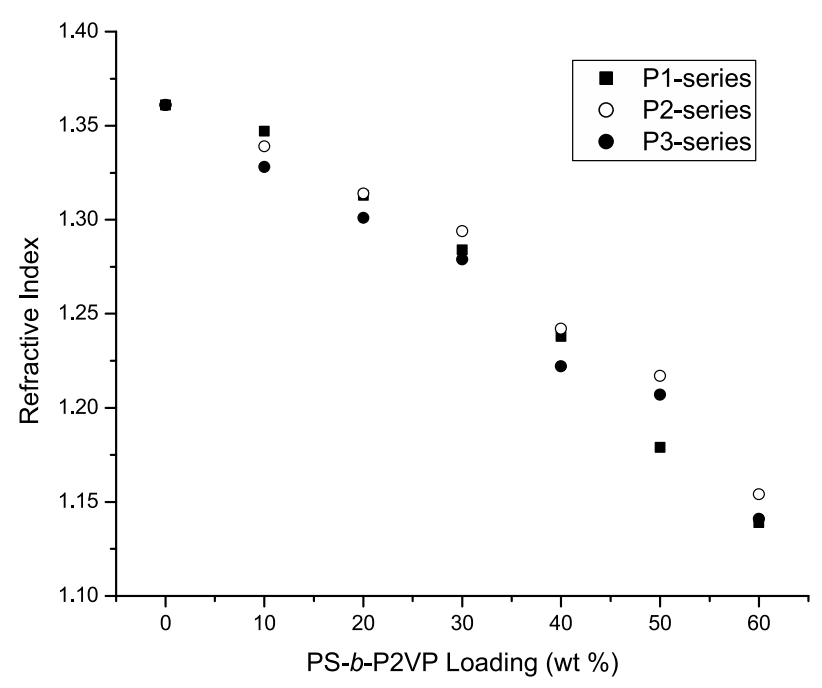

Fig. 11. Variation of the refractive index of $\mathbf{P 1}, \mathbf{P 2}$, and $\mathbf{P 3}$ with the loading ratio of the PS- $b$-P2VP.

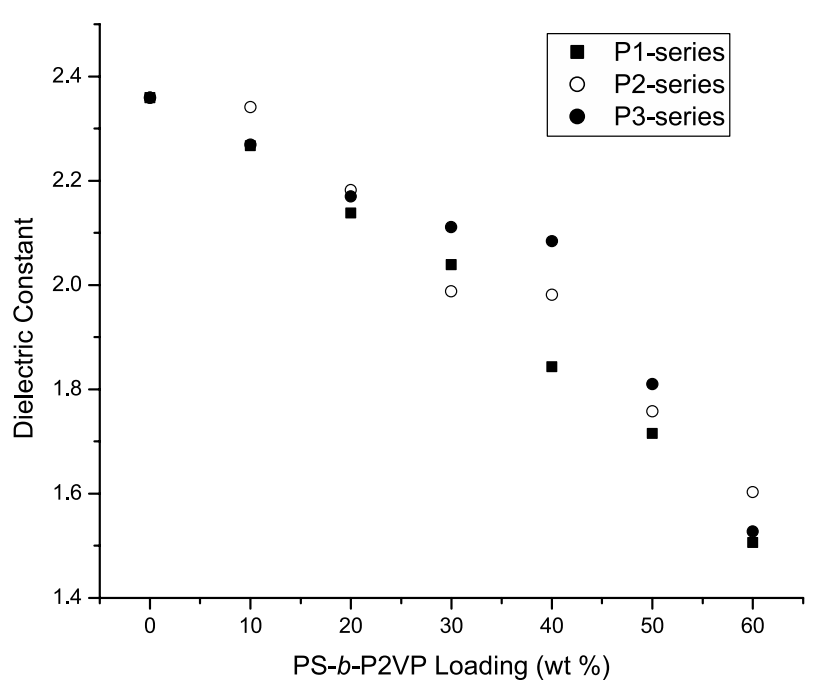

Fig. 12. Variation of the dielectric constant of P1, P2, and P3 with the loading ratio of the PS- $b-\mathrm{P} 2 \mathrm{VP}$.

P2VP significantly affected the pore morphology. The PS- $b$ $\mathrm{P} 2 \mathrm{VP}$ with a smaller $f_{\mathrm{PS}}$ requires a higher loading level to obtain the uniform pores. The refractive index and dielectric constant of the prepared nanoporous films could be tuned by the loading ratio. However, both properties are not significantly dependent on the $f_{\mathrm{PS}}$. The prepared study demonstrates the control of the morphology and properties of the nanoporous films through the polymer structure.

\section{Acknowledgements}

The authors thank the National Science Council of Taiwan (NSC 91-2216-E002-010 and NSC 91-2216-E110007) and the Department of Education of Taiwan for the financial support of this work.

\section{References}

[1] Miller RD. Science 1999;286:421.

[2] Hedrick JL, Miller RD, Hawker CJ, Carter KR, Volksen W, Yoon DY, Trollsas M. Adv Mater 1998;10:1049.

[3] Nitta SV, Pisupatti V, Jain A, Wayner PC, Gill WN, Plawsky JL. J Vac Sci Technol B 1999;17:205.

[4] Kohl AT, Mimna R, Shick R, Rhodes L, Wang ZL, Kohl PA. Electrochem Sol Lett 1999;2:77.

[5] Padovani AM, Rhodes L, Allen SAB, Kohl PA. J Electrochem Soc 2002;149:F161.

[6] Padovani AM, Riester L, Rhodes L, Allen SAB, Kohl PA. J Electrochem Soc 2002;149:F171.

[7] Lee HJ, Lin EK, Wang H, Wu WL, Chen W, Moyer ES. Chem Mater 2002; $14: 1845$.

[8] Kim HC, Wilds JB, Kreller CR, Volksen W, Brock PJ, Lee VY, Magbitang T, Hedrick JL, Hawker CJ, Miller RD. Adv Mater 2002; 14:1637.

[9] Huang QR, Volksen W, Huang E, Toney M, Frank CW, Miller RD. Chem Mater 2002;14:3676.

[10] Huang QR, Kim HC, Huang E, Mecerreyes D, Hedrick JL, Volksen W, Frank CW, Miller RD. Macromolecules 2003;36:7661. 
[11] Heise A, Nguyen C, Malek R, Hedrick JL, Frank CW, Miller RD. Macromolecules 2000;33:2346.

[12] Nguyen C, Hawker CJ, Miller RD, Huang E, Hedrick JL, Gauderon R, Hilborn JG. Macromolecules 2000;33:4281.

[13] Oh W, Hwang Y, Park YH, Ree M, Chu SH, Char K, Lee JK, Kim SY Polymer 2003;44:2519.

[14] Bolze J, Ree M, Youn HS, Chu SH, Char K. Langmuir 2001;17:6683.

[15] Kramer E, Forster S, Goltner C, Antonietti M. Langmuir 1998;14: 2027.

[16] Bronstein L, Kramer E, Berton B, Burger C, Forster S, Antonietti M. Chem Mater 1999;11:1402.

[17] Goltner CG, Berton B, Kramer E, Antonietti M. Adv Mater 1999;11: 395

[18] Yang S, Mirau PA, Pai CS, Nalamasu Q, Reichmanis E, Lin EK, Lee HJ, Gidley DW, Sun J. Chem Mater 2001;13:2762.

[19] Yang S, Mirau PA, Pai CS, Nalamasu Q, Reichmanis E, Pai JC, Obeng YS, Seputro J, Lin EK, Lee HJ, Sun J, Gidley DW. Chem Mater 2002;14:369.

[20] Xu J, Moxom J, Yang S, Suzuki R, Ohdaira T. Appl Surf Sci 2002; 194:189.

[21] Xu J, Moxom J, Yang S, Suzuki R, Ohdaira T. Chem Phys Lett 2002; 364:309.

[22] Yim CA, Lyu YY, Jeong HD, Song SA, Hwang IS, Hyeon-Lee J, Mah SK, Chang S, Park JG, Hu YF, Sun JN, Gidley DW. Adv Funct Mater 2003; $13: 382$.

[23] Li S, Li Z, Yan Y. Adv Mater 2003;15:1528.

[24] Dai CA. PhD Thesis, Cornell University; 1996. p. 17-30.

[25] Lee LH, Chen WC, Liu WC. J Polym Sci, Polym Chem 2002;40:1560.
[26] Liu WC, Yang CC, Chen WC, Dai BT, Tsai MS. J Non-Cryst Solid 2002;311:233

[27] Frisch MJ, Trucks GW, Schlegel HB, Scuseria GE, Robb MA, Cheeseman JR, Zakrzewski VG, Montgomery JA, Stratmann REJ, Burant JC, Dapprich S, Millam JM, Daniels AD, Kudin KN, Strain MC, Farkas O, Tomasi J, Barone V, Cossi M, Cammi R, Mennucci B, Pomelli C, Adamo C, Clifford S, Ochterski J, Petersson GA, Ayala PY, Cui Q, Morokuma K, Salvador P, Dannenberg JJ, Malick DK, Rabuck AD, Raghavachari K, Foresman JB, Cioslowski J, Ortiz JV, Baboul AG, Stefanov BB, Liu G, Liashenko A, Piskorz P, Komaromi, I, Gomperts R, Martin RL, Fox DJ, Keith T, Al-Laham MA, Peng CY, Nanayakkara A, Challacombe M, Gill PMW, Johnson B, Chen W, Wong MW, Andres JL, Gonzalez C, Head-Gordon M, Replogle ES, Pople JA. GAussian 98W, Revision A.11, Gaussian, Inc., Pittsburgh, PA; 2001

[28] Oh W, Shin TJ, Ree M, Jin MY, Char K. Macromol Chem Phys 2002; 203:801.

[29] Han YK, Pearce EM, Kwei TK. Macromolecules 2000;33:1321.

[30] Matsen MW. Macromolecules 1995;28:5765.

[31] Wang CY, Shen ZX, Zheng JZ. Appl Spectrosc 2000;54:209.

[32] Wang CY, Shen ZX, Zheng JZ. Appl Spectrosc 2001;55:1347.

[33] Elias HG. An introduction to polymer science. Weinheim: VCH; 1997. p. 274.

[34] Roe RJ. Methods of X-ray and neutron scattering in polymer science. New York: Oxford University Press; 2000. Chapter 5.

[35] Hashimoto T, Fujimura M, Kawai H. Macromolecules 1980;(13): 1660. 